\title{
Systematic ventriculographic studies in infants born with meningomyelocele and encephalocele. The incidence and development of hydrocephalus
}

\author{
JOHN LORBER \\ Department of Child Health, University of Sheffield (Arch Dis Child 1961;36:381-9).
}

Perhaps the interest in spina bifida has waned with the incidence falling so dramatically after the introduction of antenatal detection and termination of pregnancy. However, this paper offers an opportunity to contrast the methods of investigation of the central nervous system between the 1960 s and the present day. The case material comprised 172 infants with neural tube defects. They were all under 9 months of age ( 23 over 8 weeks old) and were studied to determine the incidence of hydrocephalus.

'The main method of investigation was ventriculography, which was often associated with dye penetration studies and sometimes with pneumoencephalography'. 'Ventriculography was performed through the right side of the anterior fontanelle'.

The conclusions were that: (1) There was an $80 \%$ incidence of hydrocephalus with meningomyelocele and encephalocele. (2) This was highest with lumbar lesions and when paraplegia was present. (3) Repair did not influence the development of hydrocephalus. (4) These diagnostic studies should be done as soon as possible so as to assess prognosis and as a guide to treatment.

Today. Within a remarkably short space of time non-invasive techniques have replaced these difficult and potentially hazardous procedures. Brain imaging, fontanometers, ${ }^{1}$ and the assessment of cerebral blood flow have almost eliminated the need for invasive procedures. Ventricular puncture is, however, still required but is a skill which, like the others replaced by surface monitoring, is less likely to be acquired by trainees in neonatology except, of course, in the parts of the world where modern expensive techniques are still unavailable. Even diagnostic lumbar puncture is, for good reason, being discouraged. ${ }^{2} 3$

Trainee neonatologists should take the oppor- tunity, should it arise, of learning how to do ventricular taps as they are at times still required for the detection of haemorrhage or infection or for the reduction of intracranial pressure. Unfortunately, as it has been pointed out by others, duty rotas today are such that a trainee may reach the point of applying for a consultant post with little or no experience of this procedure.

1 Rochefort MJ, Rolfe P, Wilkinson AR. New fontanometer for continuous estimation of intracranial pressure in the newborn. Arch Dis Child 1987;62:152-5.

2 Addy DP. When not to do a lumbar puncture. Arch Dis Child 1987;62:873-5.

3 Halliday $\mathrm{HL}$. When to do a lumbar puncture in a neonate. Arch Dis Child 1989;64:313-6.

John Lorber's first interest was in biochemistry, and he came from his native Hungary to Cambridge as an unpaid research worker in 1938 while still a medical student. He spent his whole paediatric career in Sheffield, starting as a research assistant and rising to become Professor and Head of the University Department of Child Health, retiring in 1981 . He has always professed his main interest to be in 'ordinary' nontechnical clinical paediatrics and his early interests were in tuberculosis and rheumatic fever. He is, however, best known for his contributions on the subject of neural tube defects. Such an authority did he become that patients were sent to him from all over the world and he has researched and written widely on this subject. He has contributed to numerous books and despite now being well into retirement is joint editor of a new book on Anomalies of the Foetal Head, Neck and Spine.

He was founder member and first Chairman of the Medical Committee of the Association of Spina Bifida and Hydrocephalus and was invited to organise many similar associations abroad. He has travelled widely as visiting professor with WHO and by private invitation, notably on two occasions being the Harvey Cushing Society of Neurology (USA) lecturer. Many will recall his opening paper of the 50th Anniversary of the BPA entitled 'Is your brain really necessary?' It is not surprising that his exceptional contribution to paediatrics has been recognised by many honorary memberships of learned societies, notably the Society of Research in Hydrocephalus and Spina Bifida and the BPA.

C H M WALKER 